\title{
Certain Functional and Anatomical Relations of the Cornu Ammonis of the Macaque Monkey ${ }^{1,2}$
}

\author{
II. ANATOMICAL RELATIONS
}

\author{
CHARLES L. VOTAW \\ Laboratory of Comparative Neurology, Department of Anatomy, \\ The University of Michigan, Ann Arbor, Michigan
}

In their investigations of Ammon's horn. Ramón y Cajal ('01, '11) and Lorente de Nó ('34) described collaterals of the axons of the pyramidal cells which turned away from the alveus and the fimbria, passed through the stratum lucidum, and then ran horizontally in stratum lacunosum of the molecular layer of the hippocampus toward the subiculum. Such collaterals which arise from the pyramidal cells of areas CA3 and CA4 of Lorente de Nó were first described by Schaffer and carry his name (Schaffer collaterals). Moreover, there are similar collaterals coming from other pyramidal cells of the hippocampus. Although these fibers have not been traced beyond the confines of Ammon's horn, there is clear indication that impulses may leave this area of the brain by passing over fibers other than those of the fimbria-fornix system.

In spite of these reports observers have often implied that the fornix is the only efferent pathway of the hippocampus. Indeed, Brodal ('47, page 195) stated: "There seems to be general agreement on the issue that the fornix represents the main, and probably the only, efferent pathway from the hippocampus." Most authors have assumed this statement to be correct.

In part I of this study (Votaw, '59) it was shown that stimulation of the hippocampus resulted in face and body movements. Since these movements were not eliminated by fornix section, but could not be obtained when the cornu Ammonis was separated from the subiculum, it was concluded that the impulses mediating these responses were routed through the temporal lobe cortex. The present account is a description of the degenerations which resulted from the lesions which were placed in the animals used in part I of this study with especial attention to evidence of anatomical pathways other than the fornix which are efferent with respect to the hippocampus.

As in the earlier study, the term hippocampal formation (or hippocampal complex or hippocampal area) will be used to indicate the complex of dentate gyrus, Ammon's horn and subiculum. The presubiculum, prosubiculum, subiculum, and entorhinal area will be treated as separate entities. The terms hippocampus and cornu Ammonis (Ammon's horn) will be used interchangeably. The terminology applied to the layers and the regions of the hippocampal formation is based on the work of Ramón y Cajal ('11) and Lorente de Nó ('34). The terminology used for the structures found within the hypothalamic area is that suggested by Rioch, Wislocki and O'Leary ('39) except for the mammillary body, for which reference was made to the very complete study of J. Rose ('39).

\section{MATERIAL AND METHODS}

The brains of 6 of the 10 monkeys which were described in part I of this study were suitable for microscopic examination. These 6 monkeys (Macaca mulatta and Macacus cynamolgus) were unselected with reference to sex and their weight varied from 2.4 to $14.5 \mathrm{~kg}$. No other procedures were carried out on these monkeys

1 Aid for research generously provided to Dr. Elizabeth C. Crosby by Parke, Davis and Company, Detroit, made possible the carrying out of this project.

2 Parts 1 and 2 of this study represent, in part, a dissertation submitted in partial fulfillment of the requirements for the degree of Doctor of Philosophy in The University of Michigan, 1958. 
except as explained in the previous part of this study. All the lesions were placed during sterile surgical procedures accomplished with the aid of ether anesthesia.

The survival times after the final procedure on each animal varied from two to 7 weeks. All animals were sacrificed with an overdose of a barbiturate anesthetic (evipal) and perfused intracardially with a solution of $10 \%$ formalin. The brains were then removed and fixed in $10 \%$ formalin. All such material was prepared according to the Marchi technique as modified by Swank and Davenport ('35).

In the preparation of the microscopic slides, the sections were cut from 40 to $50 \mu$ in thickness. They were then arranged serially and every 5th section mounted initially. After the original survey of the material, additional sections were mounted in the areas of primary interest. Normal monkey brain serial sections stained alternately by thionin and Weil techniques were available for comparison.

Since the Marchi method was used, it will necessarily limit the study to the degenerated myelinated paths of the central nervous system. It will be noted in these studies that some of the survival times are much longer than the usually accepted period of 14 to 21 days. Those specimens which came from the animals having long survival periods following the surgical procedure are mostly better in quality than those from animals with short survival times. This is quite in accord with the study by Smith ("56a) who has noted that differences in staining result from different survival periods. This author concluded that probably not all fibers, for reasons unknown, degenerate at the same speed. Certainly, from the study at hand, it would seem that the degeneration, at least in the hippocampal system, occurs later than has been usually expected for the primate brain.

Artefacts are a common finding in the use of this technical method. These can be eliminated, or at least reduced, as was suggested by Davenport and Swank ('35) and Smith ('56b). Smith, especially, has listed some of the artefacts and the precautions to be used in both preparing and reading the slides. In this study, these suggestions were followed as closely as possible.

The 6 animals used can be readily divided into three groups of two each according to the procedure which was carried out. In group 1, the cornu Ammonis was completely exposed unilaterally in one animal and bilaterally in the other by means of parietotemporal craniectomies. The midportions of the inferior half of the superior temporal gyrus and of the superior half of the middle temporal gyrus were removed and the temporal horn of the lateral ventricle opened on one or both sides. The hippocampus then became visible as a swelling on the ventromedial wall of the ventricle. A separate operation for each hippocampus exposed was necessary. After the stimulations already reported upon were completed (Votaw ' 59 ), an attempt was made to remove all of the cornu Ammonis unilaterally in the first animal and bilaterally in the other animal.

In group 2 the same method of exposure as that employed for group 1 was used but, since exposure of the entire hippocampus was not desired, the lesions in the temporal lobes were kept as small as possible. Only a small area of both hippocampi in each animal was exposed. A small lesion was made, by means of a brain sucker, in the area which had previously been stimulated.

The third group consisted of operations in which an electrode was placed with the aid of a No. 4 Lab-Tronics stereotaxic apparatus. After the unipolar electrodes were so placed (with a rectal plug used as the indifferent electrode ) and stimulations carried out, lesions were made by passing a D. C. current of $0.3 \mathrm{ma}$ for one minute through the circuit.

Thus, in the three groups to be considered; group 1 consists of two animals which have had complete removal of one or both of the hippocampi accompanied by a lesion in one or both temporal lobes. Group 2 is composed of two animals with small regional lesions in both hippocampi together with small lesions in both temporal lobes. Group 3 is made up of two animals with stereotaxically placed bilateral lesions in the hippocampi and very minimal damage to other parts of the brain secondary to the passage of the electrodes. 


\section{RESULTS}

The descriptions which follow report the microscopic findings in the brains of the three groups of animals just discussed, locating the lesions and describing the degeneration which resulted from them in each case. Special care has been exercised to differentiate true degenerations from artefacts, and no degenerated path is reported which could not be followed serially from the region of the lesion to the location in which terminal Marchi granules were identified.

\section{Group 1}

The lesions in the hippocampi, on one side of one animal and on both sides of the other animal, were all similar. All layers of the cormu Ammonis were interrupted in areas CA2, and for most of the areas CA1 and CA3 which are contiguous with area CA2. The gyrus dentatus escaped injury. These lesions extended for the entire length of Ammon's horn from its anterior to near its posterior superior limit, with only the most posterior superior parts escaping any injury whatsoever.

Degenerated fascicles can be traced from the area of the lesion, through what is left of the alveus bundle medial to the lesions, to the fimbria, and then to the body of the fornix. This degeneration is mostly limited to the side of the lesion with a very small amount entering the fornix body on the other side, arriving there by way of the hippocampal commissure. Such degeneration granules extend anteriorly to the level of the anterior commissure, where fibers are seen entering the precommissural and postcommissural fornix columns and the stria medullaris.

The degenerated fibers pass, in large number, in front of the anterior commissure into the lateral septal nucleus, and terminal degeneration granules are found in this nucleus in high concentration. Evidences of a smaller terminal degeneration are also present in the medial septal nucleus. Some degenerated bundles can be followed through the medial septal area into the diagonal band of Broca, where terminal degeneration granules are again found. Most of this degeneration is homolateral to the lesion, only a very small amount being found on the opposite side.
The postcommissural fornix column has degenerated granules which are easily followed to the medial mammillary nucleus, in which marked terminal degeneration is seen in the form of granules diffusely scattered over its entire extent. There is a small amount of terminal degeneration in the lateral mammillary nucleus as well. Along the path of the postcommissural fornix, fibers turn off into the anterior hypothalamic area and to the ventromedial hypothalamic nucleus, but there are only a very few terminal granules in these latter two nuclei. There are some granules posterior to the mammillary body, reaching the areas about the superior and medial aspect of the red nucleus, but they can not be followed with certainty from the postcommissural fornix columns.

The stria medullaris contains a small number of degenerated fibers which reach the habenular nucleus. There is some terminal degeneration in the habenular nucleus of each side.

In the animal having only a unilateral lesion of Ammon's horn (fig. 1), the degeneration in the body of the fornix and in the precommissural regions is very largely homolateral to the side of the lesion but the amount of degeneration in the stria medullaris and the postcommissural fornix is about equal on the two sides. This indicates a principally unilateral (homolateral) discharge of the hippocampus to the septal nuclei and other precommissural areas and a principally bilateral distribution of this discharge to the hypothalamus and habenular nuclei. The hippocampal commissure in this animal also has a large number of degenerated fibers, which can be followed to the hippocampus of the other side.

Surprisingly, in spite of the massive lesions in the hippocampi, less than $50 \%$ of the fibers in the body of the fornix, anterior to the hippocampal commissure, are degenerated. It is estimated that three fourths or more of these fibers terminate in the septal nuclei and other precommissural regions. Only the remaining one-fourth enters the postcommissural fornix and the stria medullaris. Of the total number of fibers in the postcommissural fornix, only a very small number are degenerated. This would indicate a source other than 

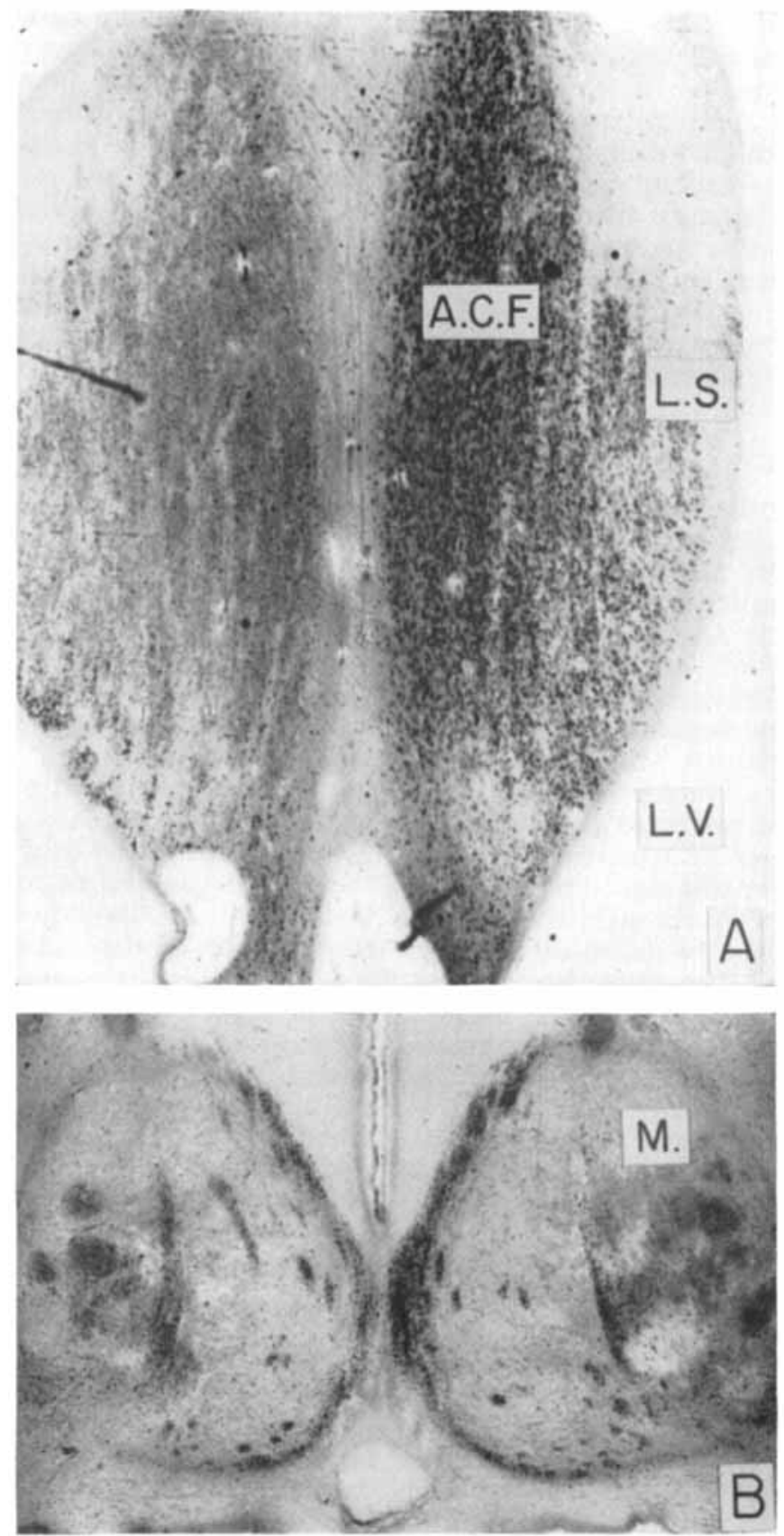

Fig. 1 Photomicrographs of brain of the monkey in group 1 who had a complete unilateral removal of the hippocampus. A, Level of the arch of the anterior column of the fornix. Note marked degeneration (black granules) in the column and the posterior aspect of the lateral septal nucleus on the side of the lesion with much less degeneration on the the opposite side. Marchi. $\times 45$. B, Mammillary bodies of the same animal. Note the equal distribution of the degeneration on the two sides. Marchi. $\times 30.5$. A.C.F., ante. rior column of the fornix; L.S., lateral septal nucleus; L.V., lateral ventricle; M., mammillary body. 
Ammon's horn for a majority of the fibers in the anterior column of the fornix.

Terminal degeneration is present in the granular and in the polymorphic cell layers of the dentate gyri. Whether this is due to direct injury from the lesion or to degenerated fibers which arise or have passed through the area of the lesion can not be ascertained.

There is fiber degeneration in the alveus and in the tangential layer of the uninjured portion of area CA1. Degenerated fibers can also be seen in the prosubiculum and in both the alvear and perforating pathways leading to the hippocampal gyrus proper. Because of the nature of the lesion, it can not be determined with accuracy whether the degeneration in the alveus and the perforating pathways is due to injury of the cornu Ammonis or destruction in the lateral hemisphere wall. However, since the concentration of the degeneration is greatest adjacent to the hippocampus and diminishes rather regularly as the distance from the hippocampus is increased, the indications are that at least some of these fibers are due to the lesion in Ammon's horn. Undoubtedly, some of these degenerated fibers are from the lesion in the lateral part of the temporal lobe and since the fibers from the temporal lobe lesion and the hippocampal lesion intermingle, obviously the origin of any particular degenerated fascicle can not be ascertained.

Degenerated fibers enter the striae of Lancisius and travel the entire length of this structure. The granules can be followed around the genu of the corpus callosum and into the anterior reaches of the hippocampal rudiment. A few fibers turn off into the cingulate gyrus along this path and a few terminal granules are found scattered through the layers of this gyrus.

The lesions in the temporal lobe have resulted in degeneration in temporotegmental and temporopontine pathways and such degenerated fascicles can be followed to their destinations. There is also a marked degeneration of corticothalamic fibers passing from the injured temporal lobe area to the anterior and lateral nuclei of the thalamus and especially to the pulvinar. The stria terminalis has been interrupted on one side and degenerated fibers can be followed along this path to the amygdaloid nucleus in one direction, and to the anterior commissure, the preoptic area, and, possibly, the septal nuclei in the other direction.

\section{Group 2}

There were 4 lesions in these two animals, one in each cornu Ammonis. All the lesions are limited to the middle half of each hippocampus. In one animal, the lesion on one side has involved all layers of area CA3 and part of the bordering CA2 for approximately one fourth of the anterior to posterior length of the hippocampus. It is located in the posterior part of the anterior third of this structure. In the other hemisphere of this same animal, the lesion involves area CA2 and a small part of area CA3 over the middle third of Ammon's horn.

In the second animal of this group, the lesion on one side has destroyed area CA3 and also has involved all the layers of the dentate gyrus as well. This destruction is present over the middle third of the length of the hippocampus. In the other hemisphere of this animal a single knife cut was made at the midpoint of the hippocampus at right angles to its long axis. This cut passed through all the layers of the dentate gyrus, and areas CA3, CA2, and most of CA1.

It should be noted that, in all cases, the alveus has been cut. Also, in two of these lesions, the dentate gyrus has been involved. In both animals there are lesions in the lateral part of the temporal lobe which are smaller than those in group 1, but still of significant size so that the degeneration from these areas must be considered.

Degenerated fibers from the side of the lesion, enter the alveus and the fimbria through which they can be traced to the fornix as before. This degeneration can be followed into the postcommissural fornix and precommissural fornix and has the same distribution as the similarly degenerated fibers described in group 1. The amount of the degeneration found in these various regions appears to be somewhat proportional to the 
amount of damage in the hippocampus, as would be expected. There is no evidence of specific localization, within the body of the fornix, of fibers from particular regions of Ammon's horn.

Both anterior and posterior to these limited lesions, degeneration is found in the alveus. Fibers can be seen leaving this bundle to enter the stratum oriens, the stratum pyramidale, and the stratum radiatum of Ammon's horn, and the polymorphic cell and the granular cell layers of the dentate gyrus. Terminal degeneration granules are found in all of these layers. In the cornu Ammonis, this terminal degeneration is present in all areas but is greater in amount in the region where the lesion is located and slightly anterior and posterior to it. For example, if the lesion is in area CA3, then the main concentration of the associated degeneration is found in area $\mathrm{CA} 3$ both anterior and posterior to the lesion. This limited series of lesions, then, affords some evidence that any given hippocampal area is associated both anteriorly and posteriorly with other areas of the hippocampal formation.

Degeneration can be followed from the region of the lesions, through the alveus bundle and into the alvear pathway as it is curving around the inferior border of the lateral ventricle. These fibers appear to turn out into both the hippocampal and the inferior temporal gyri, in which regions terminal granules can be found. Again, care must be taken in interpreting these findings because of the rather large lesions in the temporal gyri. However, this path can be followed in its entirety and can be separated from the degeneration caused by the temporal lesions, and therefore it is regarded as highly probable that these degenerated fascicles represent a hippocampotemporal pathway. This degeneration is found at all levels of the lesion and for a slight distance anterior and posterior to it.

As in group 1, the lesions in the temporal lobe have resulted in degeneration in the temporothalamic, temporopontine, and temporotegmental pathways. This degeneration is distinct and separate from that described in the hippocampal regions. There is also some cortico-cortical degeneration, which is also easily distinguishable from the hippocampal temporal degeneration.

\section{Group 3}

The lesions to be described in this group are limited to two. One was located in the midregion of the hippocampus, the other in the posterior region. Both were confined to about one fourth of the length of the hippocampus. Both involved area CA1, a small part of the contiguous area CA2, but, in one animal, the lesion extended into the prosubiculum for a short distance. There was no damage to the dentate gyrus in either case.

Again, degeneration granules could be followed into the alveus, fimbria, and fornix, and, through the fornix, distributed to all of the areas described in group 1 . The degeneration of association fibers described in group 2 is also present in these brains. However, as expected, the terminal degeneration is now more concentrated in areas CA1 and CA2, both anterior and posterior to the site of the lesion.

From the area of the lesion, definite degeneration granules can be followed through the perforating pathways and the alvear pathways to the lateral side of the lateral ventricle. The involved fibers turn away from the lesion and the alveus, continue around the inferior border of the lateral ventricle, and then ascend along the lateral side of the lateral ventricle (fig. 2). In their course, some fibers enter the hippocampal gyrus or the inferior, the middle, or the superior temporal gyrus. There is only a little evidence of degeneration beyond the confines of the temporal lobe, and the granules can not be followed to any specific region with certainty. The electrode paths have passed through the cortical structures to reach the hippocampal area. However, there is no significant degeneration from such cortical areas, and it is believed that the degeneration in the temporal cortex is due to the lesion in the cornu Ammonis. Again the result suggests the existence of a hippocampotemporal pathway.

In résumé, a study of the microscopic material has shown: (1) Lesions of the hippocampus result in degeneration of the fibers within the fornix, although the 

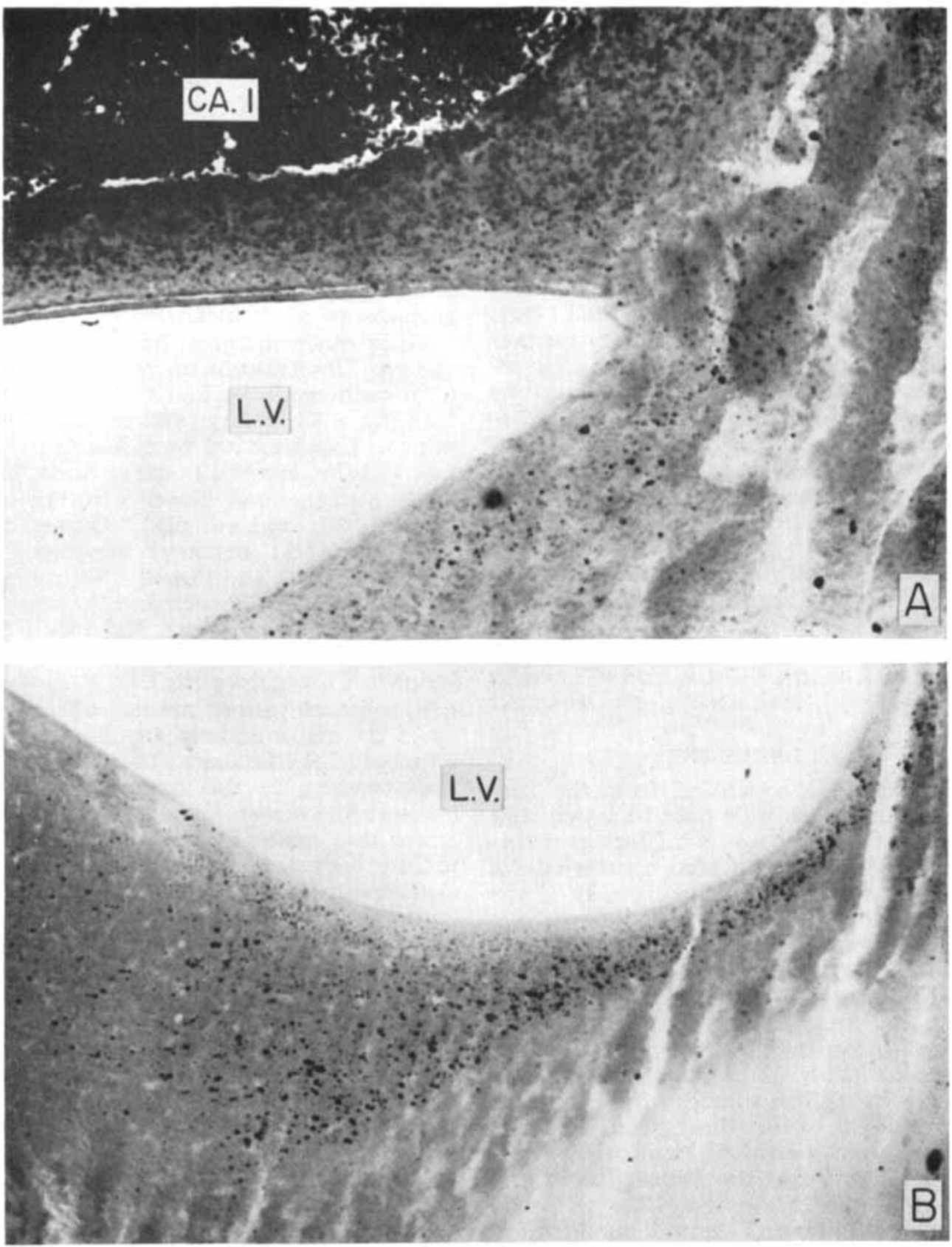

Fig. 2 Photomicrographs of brain of a monkey in group 3 with a stereotaxically placed lesion in the hippocampus. A, Note the edge of the lesion in the hippocampus and the degenerated fibers curving around the inferior edge of the lateral ventricle and entering the cortex on the lateral side (bottom of photographs) of the ventricle. Marchi. $\times 94$. B, Same monkey showing degeneration all along the lateral side of the lateral ventricle with some fibers turning into the temporal lobe gyri. Marchi. $\times 50$. L.V., lateral ventricle; CA1, area CA1 of the hippocampus. 
amount of such fibers, following almost complete destruction of the hippocampus is still less than $50 \%$ of the total number of fibers in the body of the fornix. (2) The largest proportion of the fibers degenerated in the fornix as a result of hippocampal lesions enters the precommissural fornix column and ends mainly in the lateral septal nucleus with some small distribution to the medial septal nucleus and the diagonal band of Broca. (3) A smaller number of fibers enters the postcommissural fornix and ends chiefly in the medial mammillary nucleus with a small distribution to other hypothalamic nuclei; another small group passes through the stria medullaris to the habenular nuclei. (4) Postmammillary fornix fibers have been indicated but not definitely demonstrated. (5) Intrahippocampal association fibers can be traced both anterior to and posterior to the lesions in Ammon's horn. (6) Degenerated fibers resulting from lesions in cornu Ammonis turn out into the white matter of the temporal lobe and end in the hippocampal gyrus, the inferior and the middle temporal gyri, and the superior temporal gyrus.

\section{DISCUSSION}

Brodal ('47) concluded from the anatomic and physiologic data at hand, that the hippocampus was an effectory structure. The fornix has been considered for some time as the efferent pathway of the hippocampus. This has not always been true. Prior to the work of Ramón y Cajal done in 1901 (and reviewed by him in 1911) it was assumed that the fimbria was the main afferent supply to the cornu Ammonis. Cajal concluded that the afferent supply to Ammon's horn was mainly from three sources (from the area entorhinalis, from the gyrus limbicus through the cingulum, and the striae Lancisii) and that the fimbria-fornix system was chiefly efferent.

In descriptions of normal mammalian material, many of the earlier authors ( $\mathrm{Ra}$ món y Cajal, '01, '11; Lorente de Nó, '33, '34; and others reported in Kappers, Huber, and Crosby, '36) described various connections of the fornix to the habenula, the anterior thalamic nuclei, the septal area, the nucleus accumbens, the preop- tic area, the diagonal band of Broca, the mammillary body, the hypothalamus anterior to the mammillary body, and the midbrain posterior to the mammillary body. Nauta ('56), using a silver technique designed by himself confirmed all of these connections in the rat. Gerebtzoff (' 39, ' 42 ), in addition to the above connections, found fibers to the pineal body, the lateral hypothalamic area, and the tegmentum near the raphé in the guinea pig. He considered all such connections to be homolateral.

Many other observers have studied this system. Observations on normal material have been made by Loo ('31, opossum), Marburg ('44, man), and Jeserich ('45, mink). Experimental work has been carried out by Fox ('43, cat), Allen ('44, dog), Sprague and Meyer ('50, rabbit), Morin ('50, guinea pig), Crosby and Woodburne ('51, monkey), Simpson ('52, monkey), Daitz and Powell ('54, rat, rabbit, and monkey), Powell and Cowan ('55, rat, rabbit, and monkey), McLardy ('55a, '55b, monkey), Guillery ('56, rat), and Johnson ('59, guinea pig).

In spite of various species differences, all of the above authors are in agreement on most of the findings. All report fornix fibers ending in the mammillary body. Sprague and Meyer, and also Guillery, suggested that some of the fibers to the mammillary body are crossed. In the present experiments it was noted that the degeneration in the mammillary bodies is almost always equal, and indicates a bilateral distribution to this area. Many authors have indicated that there is a postmammillary component of the postcommissural fornix column; however, this varies in size among the mammalian species, being found particularly clearly in the rabbit and the rat. The degeneration described in this paper neither proves nor disproves the presence of any postmammillary fibers in the fornix system of the monkey.

The earlier authors mentioned found fibers of the postcommissural fornix ending in other hypothalamic nuclei as well as in the mammillary body. While most of the recent authors neglect to comment on this fact, Powell and Cowan ('55) and Crosby and Woodburne ('51) found them, Allen ('44) suggested that they were present, 
and Sprague and Meyer denied their existence ('50). Since in the Marchi technique the actual ending of the fibers can not be found, the results are only suggestive, but it is very probable that such fibers extend at least to the ventromedial hypothalamic nucleus.

None of the previous investigators has mentioned the proportion of fibers in the postcommissural fornix which arise in the hippocampus. Certainly, according to the experiments here reported, very few ibers of the postcommissural column originate in this area since massive lesions in cornu Ammonis resulted in only a small partial degeneration of the column. It is evident that part of the discharge to the mammillary body and to the other hypothalamic nuclei originates in areas other than the hippocampus.

Many observers have noted a discharge from the fornix into the dorsal thalamic structures, mainly the anterior thalamic nucleus. Nauta ('56) has recently reported such a connection. Guillery ('56) also observed this termination. Other workers have not mentioned it and it must be assumed that such fibers were not found. Neither are any such fibers degenerated in the present experiments.

Nauta ('56) and Marburg ('44) are recent experimentalists who have described a habenular connection in the fornix. Sprague and Meyer ('50) did not find one. The present experiments show that this connection is small, but present, and is bilateral in distribution, at least for the monkey.

Again, the earlier authors reported precommissural fornix fibers ending in the septal nuclei, the nucleus accumbens, the preoptic area, and the diagonal band of Broca. Fox ('43) found Marchi degeneration in the lateral septal nucleus as did Jeserich ('45). McLardy ('55b) reported a moderate termination in this nucleus after the fornix fibers had crossed, but most observers have found these endings to be homolateral. In the degeneration studies at hand, there is a marked degeneration in the lateral septal nucleus, with a partial degeneration on the opposite side, signifying some (though very little) crossing, of the precommissural fornix fibers. In the experiments here reported there is also degeneration in the diagonal band of Broca. No degeneration was found in the nucleus accumbens or in the preoptic area that could be clearly differentiated as being of fornix origin.

It is surprising that even after almost complete destruction of Ammon's horn, the degeneration found in the body of the fornix is less than $50 \%$ of the total number of fibers there. This would seem to indicate that some of the fibers in the body of the fornix originate from regions other than the hippocampus. It is difficult, then, to agree with Allen ('44) that all of the fibers of the fornix are hippocampal in origin. McLardy ('55b) in the monkey and Daitz and Powell ('54) in the rat, the rabbit, and the monkey reported retrograde cell degeneration in the medial septal nucleus after transection of the body of the fornix. Kappers, Huber, and Crosby ('36), and Morin ('50) described septoammonic paths within the fornix. These same paths were denied by Ramón y Cajal ('11) and Lorente de Nó ('34). Most of the present anatomical investigations also deny such fibers. By the evoked potential technique, Campbell and Sutin ('53) and Green and Adey ('56) obtained responses in the hippocampus on stimulation of the septal area. Green and Arduini ('53, '54) noted that the hippocampal responses to brain stem stimulation, and to visual, auditory, and somatic stimuli, were eliminated by lesions of the fornix and the septal region. Cragg and Hamlyn ('57) and Stoll, Ajmone-Marsan, and Jasper ('51) picked up impulses in the presubiculum and the temporal pole following stimulation of the septal area in the rabbit and the cat. Votaw ('60) in a combined stimulation and degeneration experiment, showed the presence of septoammonic fibers in the monkey. Such observations indicate that the septal area discharges to the hippocampal region and that these discharges take place through the fornix system. Thus we can not agree with many authors that the fornix is solely an efferent tract with respect to the hippocampus.

As alluded to by some authors (Ramón y Cajal, '11; Lorente de Nó, '34), there is evidence in this series of experiments that intrahippocampal association fibers exist. 
These appear to be localized within Lorente de Nós areas and oriented in a longitudinal fashion. Localized lesions of the hippocampus result in degeneration in the hippocampal layers both anterior and posterior to the lesion. Morin ('50) also found such fibers.

Although no precise localization pattern can be mapped according to the present set of experiments, it is noted that there is a definite efferent discharge of the cornu Ammonis which is projected to most of the temporal lobe. This is given further importance when somatic motor responses secondary to stimulation of the hippocampus are not eliminated by fornix section, but are eliminated by separating it from the subiculum, as reported in part I of this study (Votaw, "59). Thus, it is very difficult to agree with the general feeling that the fornix represents the only known efferent pathway of the hippocampus. Morin and Green ('53) and Green and Adey ('56) found, by evoked potential technique, that stimulation of the hippocampus resulted in a discharge into the lateral part of the temporal lobe. Such discharge was not eliminated by fornix section. It appears that the efferent discharge of the hippocampus by way of the temporal lobe is an important one.

The author has suggested in part I of this study that the hippocampus projects to the temporal lobe area where it is known that motor responses of an extrapyramidal nature can be obtained (Votaw, 59). He thus concluded that the movements obtained from stimulation of the hippocampus, also reported in part $I$, are, perhaps, a part of the normal functioning of the hippocampus, mediated by way of the temporal lobe and not by way of the fornix. The degeneration studies here reported support this view in that they indicate, anatomically, the presence of a hippocampotemporal pathway.

\section{CONCLUSIONS}

1. An investigation of the degeneration resulting from various lesions placed in the cornu Ammonis of the monkey has been carried out utilizing the Marchi technique.
2. Degeneration from such lesions is found in the fornix and the previously reported distribution of these fibers, as found in the literature, has been documented except that no degeneration was found in the preoptic area, nucleus accumbens, anterior thalamic nucleus, pineal body, and not definitely shown for postmammillary areas.

3. A rich intrahippocampal associative connection has been indicated.

4. In addition to the well known connections of the cornu Ammonis, a definite and important efferent hippocampotemporal path, discharging from the hippocampus to the hippocampal gyrus and to other gyri of the temporal lobe, has been identified.

\section{ACKNOWLEDGMENT}

The author again wishes to express his sincerest appreciation for the help given him by Dr. Elizabeth Crosby who was his adviser during this research project and also the chairman of his doctoral committee under whose direction this work was accomplished. Her generous assistance, valuable advice, and patient encouragement served as an inspiration throughout the entire project.

\section{LITERATURE CITED}

Allen, W. F. 1944 Degeneration in the dog's mammillary body and Ammon's horn following transection of the fornix. J. Comp. Neur., 88: 283-291.

Brodal, A. 1947 The hippocampus and the sense of smell. Brain, 70: 179-224.

Campbell, B., and J. Sutin 1953 Excitability states in the hippocampal pyramidal layer. Trans. Amer. Neur. Assoc., 80th meeting, pp. 92-95.

Cragg, B. G., and L. H. Hamlyn 1957 Some commissural and septal connexions of the hippocampus in the rabbit. A combined histological and electrical study. J. Physiol, 135: 460485.

Crosby, E. C., and R. T. Woodburne 1951 The mammalian midbrain and isthmus regions. II. The fiber connections. C. The hypothalamotegmental pathways. J. Comp. Neur., 94: 1-32.

Daitz, H. M., and T. P. S. Powell 1954 Studies of the connexions of the fornix system. J. Neur. Neurosurg. Psychiat., 17: 75-82.

Davenport, H. A., and R. L. Swank 1935 Artefacts and the effects of perfusions on the Marchi technique. Stain Tech., 10: 45-52.

Fox, C. A. 1943 The stria terminalis, longitudinal association bundle and precommissural formix fibers in the cat. J. Comp. Neur., 79: 277-291. 
Gerebtzoff, M. A. 1939 Sur quelques voies d' association de l'ecorce cerebrale. J. Belge. Neur. Psychiat., 39: 205-221.

1942 Note anatomo-experimentale sur le fornix, la corne d'Ammon et leurs relations avec diverses structures encephaliques, notamment l'epiphyse. Acta. Neur, et Psychiatrica Belge., 42: 199-206.

Green, J. D., and W. R. Adey 1956 Electrophysiological studies of hippocampal connections and excitability. Electroencephalog. Clin. Neurophysiol., 8: 245-262.

Green, J. D., and A. A. Arduini 1953 Rhinencephalic responses to afferent stimulation. 19th internat. Physiol. Congress, Abstracts of Communications, pp. 409-410.

- 1954 Hippocampal electrical activity in arousal. J. Neurophysiol., 17: 533-557.

Guillery, R. W. 1956 Degeneration in the postcommissural fornix and the mammillary peduncle of the rat. J. Anat., 90: 350-371.

Jeserich, M. W. 1945 The nuclear pattern and the fiber connections of certain non-cortical areas of the telencephalon of the mink (Mustela visson). J. Comp. Neur., 83: 173-211.

Johnson, T. N. 1959 Studies on the brain of the guinea pig. II. The olfactory tracts and fornix. Ibid., 112: 121-140.

Kappers, C. U. Ariëns, G. C. Huber and E. C. Crosby 1936 The Comparative Anatomy of the Nervous System of Vertebrates Including Man. The MacMillan Co., New York.

Loo, Y. T. 1931 The forebrain of the opossum, Didelphis virginiana. Part II. Histology. J. Comp. Neur., 52: 1-148.

Lorente De Nó, R. 1933 Studies on the structure of the cerebral cortex. J. Psychol. Neurol., 45: $381-438$.

- 1934 Studies of the structure of the cerebral cortex. II. Continuation of the study of the Ammonic system. Ibid, 46: 113-177.

Marburg, $O$. 1944 The structure and fiber connections of the human habenula. J. Comp. Neur., 80: 211-234.

McLardy, T, 1955a Observations on the fornix of the monkey. I. Cell studies. Ibid., 103: 305-325.

- $1955 \mathrm{~b}$ Observations on the fornix of the monkey. II. Fiber studies. Ibid., 103: 327-344.

Morin, F. 1950 An experimental study of hypothalamic connections in the guinea pig. Ibid., 92: 193-214.
Morin, F., and J. D. Green 1953 Diffuse after discharges following stimulation of the fimbria hippocampi. Am. J. Physiol., 175; 251-257.

Nauta, W. J. H. 1956 An experimental study of the fornix system in the rat. J. Comp. Neur., 104: 247-272.

Powell, T. P. S., and W. M. Cowan 1955 An experimental study of the efferent connexions of the hippocampus. Brain, 78: 115-132.

Ramón y Cajal, S. 1901 Trabajos del laboratorio de investigaciones biologicase de la Universidad de Madrid, Tomo I. Parts of this paper are translated to English by L. M. Kraft in Ramón y CajaI, S. 1955 Studies on the cerebral cortex, limbic structures. The Year Book Publ., Chicago, Ill.

- 1911 Histologie du système nerveus de l'homme et des vertébrés. A. Maloine, Ed., Paris.

Rioch, D. McK., G. B. Wislocki and J. L. O'Leary 1939 A precís of preoptic, hypothalamic, and hypophyseal terminology with atlas. Res. Pub. Assoc. Res. Nerv. Ment, Dis., 20: 3-30.

Rose, J. E. 1939 The cell structure of the mammillary body in the mammals and in man. J. Anat., 7: 91-115.

Simpson, E. A. 1952 The efferent fibers of the hippocampus in the monkey. J. Neur. Neurosurg. Psychiat., 15: 79-92.

Smith, M. C. 1956a Observations on the extended use of the Marchi method. Ibid., 19: $67-73$.

$1956 \mathrm{~b}$ The recognition and prevention of artefacts of the Marchi method. Ibid., 19: $74-83$.

Sprague, J. M., and M. Meyer 1950 An experimental study of the fornix in the rabbit. $J$. Anat., 84: 354-368.

Stoll, J. C., Ajmone-Marsan and H. H. Jasper 1951 Electrophysiological studies of subcortical connections of anterior temporal regions in cat. J. Neurophysiol., 14: 305-316.

Swank, R. L., and H. A. Davenport 1935 Chlorate-osmic-formalin method for staining degenerating myelin. Stain Tech., 10: 87-90.

Votaw, C. L. 1959 Certain functional and anatomical relations of the cornu Ammonis of the macaque monkey. I. Functional relations. J, Comp. Neur., 112: 353-382.

1960 Study of septal stimulation and ablation in the Macaque monkey. Neurol, 10: 202-209. 